\title{
Interval training as an alternative modality to continuous exercise in patients with COPD
}

\author{
I. Vogiatzis, S. Nanas, C. Roussos
}

Interval training as an alternative modality to continuous exercise in patients with COPD. I. Vogiatzis, S. Nanas, C. Roussos. C) ERS Journals Ltd 2002.

ABSTRACT: Understanding of what constitutes a training load adequate to induce training effects in patients with chronic obstructive pulmonary disease (COPD) is still evolving. The present study investigated whether interval training (IT) is effective in terms of inducing measurable improvements in physiological response and compared its effects on exercise tolerance (ET) and quality of life to those of continuous training (CT).

Thirty-six COPD patients, with a forced expiratory volume in one second of $45 \pm 4 \%$ of the predicted value (mean \pm SEM), were randomly assigned to CT (exercise at $50 \%$ of baseline peak work-rate) or IT (work for $30 \mathrm{~s}$ at $100 \%$ of peak work-rate alternating with 30-s rest intervals) groups that cycled $40 \mathrm{~min} \cdot \mathrm{day}^{-1}$ and 2 days $^{-w_{e} k^{-1}}$ for 12 weeks.

After training, both groups showed significantly improved ET (IT, $57 \pm 6$ to $71 \pm 8 \mathrm{~W}$; CT, $57 \pm 5$ to $70 \pm 6 \mathrm{~W}$ ) and total quality-of-life score of the Chronic Respiratory Disease Questionnaire (IT, $77 \pm 3$ to $88 \pm 2$; CT, $78 \pm 3$ to $93 \pm 2$ ). At identical levels of exercise, minute ventilation was significantly reduced (IT, $35.8 \pm 2.5$ to 31.7 $\pm 2.5 \mathrm{~L} \cdot \mathrm{min}^{-1}$; $\mathrm{CT}, 36.4 \pm 2.7$ to $\left.32.5 \pm 2.7 \mathrm{~L} \cdot \mathrm{min}^{-1}\right)$. The magnitude of improvement in these variables was not significantly different among groups.

The present data expand on the principles of exercise prescription for chronic obstructive pulmonary disease patients by demonstrating that interval training elicits substantial training effects, which are similar in magnitude to those produced by continuous training at half the exercise intensity but double the exercise time.

Eur Respir J 2002; 20: 12-19.
National and Kapodistrian University of Athens, Medical School, Dept of Pulmonary and Critical Care Medicine, Cardiopulmonary Rehabilitation Centre, Eugenidion Hospital, Athens, Greece.

Correspondence: I. Vogiatzis, National \& Kapodistrian University of Athens, Medical School, Dept of Pulmonary and Critical Care Medicine, Eugenidion Hospital, 2nd Floor, 20 Papandiamantopoulou Str. 115-28, Ilisia, Athens, Greece.

Fax: 30107242785

E-mail: vogiatzis@hotmail.com

Keywords: Chronic obstructive pulmonary disease, dyspnoea, exercise tolerance, interval training

Received: July 312001

Accepted after revision: December 26 2001

This study was supported by a grant from the Greek General Secretariat for Research and Development.
Dyspnoea associated with insufficient mechanical ventilatory reserve [1] and skeletal muscle dysfunction [2] are the principal factors that limit exercise tolerance in patients with chronic obstructive pulmonary disease (COPD). There is currently a compelling body of evidence that exercise training induces considerable physiological effects and improves measures of exercise tolerance; as such it represents a cornerstone of the interdisciplinary management of COPD patients in pulmonary rehabilitation [3].

High-intensity continuous exercise training $(80 \%$ of baseline peak work-rate (WR) (PWR)) has been shown by CASABURI et al. [4] to be superior to lowintensity exercise $(50 \%$ PWR) when the same total work is performed by two groups of patients characterised by moderate airflow limitation (forced expiratory volume in one second (FEV1) $56 \%$ of the predicted value). Further studies, by Maltais et al. [5] and CASABURI et al. [6], however, reported that the majority of patients characterised by severe airflow limitation (FEV1 38 and 36\% pred, respectively) were not able to sustain prolonged high-intensity $(80 \%$

For editorial comments see page 4.
PWR) exercise for either the entire duration [5] or several weeks of the rehabilitation programme [6].

A well-established alternative strategy that allows high-intensity exercise to be performed for a relatively long period is interval training (IT), i.e. repeated periods of maximal or high-intensity exercise alternating with corresponding short intervals of rest. Early studies in healthy subjects showed that more work can be performed before exhaustion sets in by exercising with intervals than when the same total amount of work is performed continuously [7-9]. Gosselink et al. [10] and Coppoolse et al. [11] examined the effects of IT on measures of exercise tolerance and compared its efficacy to that of continuous exercise in COPD patients. These studies revealed no significant differences between the two training modalities in terms of improvement in exercise tolerance. Interestingly, the study of Coppoolse et al. [11] reported that IT did not induce a reduction in ventilatory demand at a given exercise level. Furthermore, in the nonrandomised study of Gosselink et al. [10], the most severe patients were assigned to the interval group, whereas, in the randomised trial of COPPOOLSE et al. [11], patients 
assigned to IT received a combination of high- and low-intensity sessions. It is, therefore, probable that the effectiveness of IT in these two studies, both in absolute terms and relative to continuous exercise, might have been underestimated. Therefore, the present study was designed with a two-fold purpose: first, to investigate whether a training programme that consisted of maximal-intensity interval exercise sessions could be effective in terms of inducing measurable improvements in physiological response; and, secondly, to compare the effects of the two modalities on exercise tolerance, intensity of breathlessness and quality of life (QoL) in patients with moderately severe COPD.

\section{Methods}

\section{Patient inclusion criteria}

Thirty-six outpatients with COPD defined as moderate to severe using American Thoracic Society criteria were referred to the rehabilitation programme by their attending chest physicians (table 1). Prior to entering the study, the patients were clinically stable and met the following criteria: 1) postbronchodilator FEV1 $<60 \%$ pred and FEV1/forced vital capacity (FVC) $<65 \%$ without significant reversibility $(<15 \%$ change in initial FEV1); 2) optimised medical therapy; and 3) no clinical evidence of exercise-limiting cardiovascular or neuromuscular diseases.

Table 1. - Physical characteristics, pulmonary function and exercise capacities of patients at the outset of the study

\begin{tabular}{|c|c|c|}
\hline & Interval group & Continuous group \\
\hline Males/females n & $14 / 4$ & $16 / 2$ \\
\hline Age yrs & $67 \pm 2$ & $69 \pm 2$ \\
\hline Weight kg & $77 \pm 3$ & $76 \pm 3$ \\
\hline Height $\mathrm{cm}$ & $166 \pm 2$ & $167 \pm 2$ \\
\hline FEV1 L & $1.16 \pm 0.09$ & $1.13 \pm 0.09$ \\
\hline$\%$ pred & $45.4 \pm 3.9$ & $44.4 \pm 3.6$ \\
\hline FVC L & $2.24 \pm 0.13$ & $2.17 \pm 0.11$ \\
\hline$\%$ pred & $64.7 \pm 4.8$ & $65.6 \pm 3.8$ \\
\hline$D \mathrm{~L}, \mathrm{CO} \%$ pred & $58.3 \pm 5.6$ & $52.2 \pm 5.1$ \\
\hline $\mathrm{Pa}, \mathrm{O}_{2} \mathrm{mmHg}$ & $71 \pm 2$ & $71 \pm 2$ \\
\hline$P \mathrm{a}, \mathrm{CO}_{2} \mathrm{mmHg}$ & $40 \pm 2$ & $41 \pm 1$ \\
\hline Arterial pH & $7.41 \pm 0.06$ & $7.43 \pm 0.02$ \\
\hline Peak work-rate W & $57 \pm 6$ & $57 \pm 5$ \\
\hline Peak $V^{\prime} \mathrm{O}_{2} \mathrm{~L} \cdot \mathrm{min}^{-1}$ & $1.06 \pm 0.06$ & $1.09 \pm 0.06$ \\
\hline$\%$ pred & $54.8 \pm 3.4$ & $55.7 \pm 3.5$ \\
\hline Peak $V_{E}^{\prime} \mathrm{L} \cdot \mathrm{min}^{-1}$ & $35.8 \pm 2.5$ & $36.4 \pm 2.7$ \\
\hline $\mathrm{LT} \mathrm{L} \cdot \mathrm{min}^{-1}$ & $0.81 \pm 0.05$ & $0.78 \pm 0.04$ \\
\hline Peak $f \mathrm{C}$, beats $\cdot \mathrm{min}^{-1}$ & $128 \pm 4$ & $122 \pm 4$ \\
\hline Peak $S_{\mathrm{p}, \mathrm{O}_{2}} \%$ & $94 \pm 1$ & $92 \pm 1$ \\
\hline
\end{tabular}

Data are presented as mean \pm SEM. FEV1: forced expiratory volume in one second; FVC: forced vital capacity; $D \mathrm{~L}, \mathrm{CO}$ : diffusion capacity of the lung for carbon monoxide; $P \mathrm{a}, \mathrm{O}_{2}$ : arterial oxygen tension; $\mathrm{Pa}_{\mathrm{a}} \mathrm{CO}_{2}$ : arterial carbon dioxide tension; $V^{\prime} \mathrm{O}_{2}$ : oxygen uptake; $V_{\mathrm{E}}^{\prime}$ : minute ventilation; LT: lactate threshold; $f \mathrm{C}$ : cardiac frequency; $S_{\mathrm{p}, \mathrm{O}_{2}}$ : arterial oxygen saturation measured by pulse oximetry; \% pred: percentage of the predicted value. $(1 \mathrm{mmHg}=0.133 \mathrm{kPa}$; $1 \mathrm{kPa}=7.5 \mathrm{mmHg}$.).

\section{Study design}

The study was designed as a randomised controlled parallel two-group study. Once it was verified that the patients met the selection criteria, they were randomly assigned to one of the two training modalities: interval or continuous. Stratified randomisation was used to achieve approximate balance of the important characteristics (table 1), including FEV1 ( $\leqslant$ or $>50 \%$ pred) and PWR ( $\leqslant$ or $>70 \mathrm{~W}$ ) as assessed by rampincremental cycle ergometer test (see below), in the continuous (CT) and IT groups. Within each stratum, patients were randomly assigned. All patients gave informed consent and the protocol was approved by the Institutional Research Review Panel of Eugenidion Hospital on issues of ethics, health and safety.

\section{Outcome measurements}

Within 1 week before and after the end of the training programme, patients visited the laboratory for a half-day session and performed pulmonary function and cardiopulmonary exercise tests on the cycle ergometer.

Pulmonary function tests. Spirometry for the determination of FEV1 and FVC was performed in the sitting position using a spirometer (Masterlab; Jaeger, Würzburg, Germany) according to recommended techniques [12]. Lung diffusion capacity for carbon monoxide (DL,CO) was determined via the singlebreath method. Maximum voluntary ventilation (MVV) was estimated by multiplying the FEV1 by 40 [13]. Arterial blood was drawn by puncture of the radial artery at rest while breathing room air for the analysis of arterial oxygen tension $\left(\mathrm{Pa}, \mathrm{O}_{2}\right)$, carbon dioxide tension, oxygen saturation $\left(\mathrm{Sa}_{\mathrm{a}} \mathrm{O}_{2}\right)$ and $\mathrm{pH}$ (ABL330; Radiometer, Copenhagen, Denmark).

Cycle ergometer test. After a 2-min rest, followed by 2 min unloaded pedalling, each subject performed a ramp-incremental (1-min increments of 5 or $10 \mathrm{~W}$ ) test to the limit of tolerance on an electromagnetically braked cycle ergometer (Ergoline 800; Sensor Medics, Anaheim, CA, USA). PWR was defined as the highest work level reached and maintained at a pedalling frequency of $\geqslant 50$ revolutions per minute for $30 \mathrm{~s}$. Patients breathed through a mouthpiece with a nose clip in place. Pulmonary gas exchange and ventilatory variable measurements were obtained from calibrated signals derived from rapidly responding gas analysers and a mass flow sensor (Vmax 229; Sensor Medics). The following variables were recorded breath by breath: pulmonary oxygen uptake $\left(V^{\prime} \mathrm{O}_{2}\right)$, pulmonary carbon dioxide output $\left(V^{\prime} \mathrm{CO}_{2}\right)$, respiratory exchange ratio, minute ventilation $\left(V^{\prime} \mathrm{E}\right)$, tidal volume $(V \mathrm{~T})$, and respiratory frequency $(f \mathrm{R})$. Cardiac frequency $(f \mathrm{C})$ was determined using the R-R interval from a 12-lead on-line electrocardiogram and $\mathrm{Sa}_{\mathrm{a}} \mathrm{O}_{2}$ by pulse oximetry $\left(S_{\mathrm{p}}, \mathrm{O}_{2}\right)$. Subjects were also asked to rate shortness of breath every 2 min using the $0-10$ Borg category ratio scale [14]. The peak $V^{\prime} \mathrm{O}_{2}$ of the ramp-incremental test were compared with those of JONES [15]. In addition, 
the slope of $V^{\prime} \mathrm{O}_{2} / \mathrm{WR}$ was calculated. The $\mathrm{V}$-slope technique was used to detect the $V^{\prime} \mathrm{O}_{2}$ at which the lactate threshold (LT) occurred [16]. Identification of the LT was made blindly and independently by two observers on both pre- and post-training exercise data sets.

Quality of life. QoL was measured using the Chronic Respiratory Disease Questionnaire (CRDQ) developed by GuYATT et al. [17]. The questionnaire was administered within 1 week before and after the end of the rehabilitation programme.

\section{Rehabilitation programme}

The rehabilitation programme was multidisciplinary and included two different modalities of supervised exercise training (continuous or interval), breathing control and relaxation techniques, methods of clearance of pulmonary secretions (performed by physical therapists), disease education and instruction in the use of medication (performed by a pneumologist), dietary advice (given by a dietician), and psychological support on issues relating to chronic disability (administered by a psychiatrist). Specific written instructions in the form of a booklet were given to patients in order to enable them to practice upper body and breathing exercises at home.

\section{Exercise prescription}

The exercise prescription was designed to present patients with the same overall training load. Patients assigned to the CT group were instructed to exercise on electromagnetically braked cycle ergometers (Cateye Ergociser, EC1600; Cat Eye Co., Ltd, Osaka, Japan) at an intensity which was initially equivalent to $50 \%$ of baseline PWR for $40 \mathrm{~min} \cdot \mathrm{day}^{-1}$ and 2 days $\cdot$ week $^{-1}$ for 12 weeks. Patients assigned to the IT group were instructed to exercise for the same period of time, weekly frequency and total duration as the CT group but at an intensity that was initially equivalent to $100 \%$ of baseline PWR with $30 \mathrm{~s}$ work interspersed with $30 \mathrm{~s}$ rest. Therefore, at the outset of the study, the total exercise time and amount of work done per session by each member of the IT group was designed to equate to the work that these patients would have done had they been assigned to the CT group. One of the training principles [18] requires that exercise intensity should be optimally maintained relative to peak exercise capacity and should parallel the improvement in physical status throughout the exercise programme [19-21]. Therefore, it was decided to increase the training intensity by an equal magnitude in both groups on a monthly basis so that, during the second and third months, it represented 60 and $70 \%$ and 120 and $140 \%$ of the baseline PWR in the CT and IT groups, respectively. Supervision during exercise sessions was conducted by physical therapists and involved measurements of $f \mathrm{C}, \mathrm{Sp}, \mathrm{O}_{2}$ and dyspnoea, using the Borg scale. Supplemental oxygen was used during training sessions for two patients in the IT group and four in the CT group because of exercise-induced oxygen desaturation $\left(\mathrm{Sp}_{\mathrm{p}} \mathrm{O}_{2}<90 \%\right)$.

\section{Statistical analysis}

Data are presented as mean \pm SEM. The percentage difference in physiological variables before and after training interventions were calculated. The withinand between-group differences were analysed using repeated measures analysis of variance. Betweengroup comparisons of baseline characteristics were carried out using an unpaired t-test, after checking for normal distribution. The level of significance was set at $\mathrm{p}<0.05$.

\section{Results}

\section{Patient recruitment}

A total of 45 patients were initially enrolled. Of these, 36 completed the rehabilitation programme, 18 in each group. Nine patients failed to complete the programme because of intercurrent pulmonary infection or noncompliance with the training schedule. Five of these had been assigned to the IT group and four to the CT group. Their characteristics were not significantly different from those of the remaining patients.

\section{Patient characteristics}

The general characteristics of the two groups before training are presented in table 1. In summary, the groups were characterised by moderately severe airflow limitation (FEV1 $\sim 45 \%$ pred), moderate hypoxaemia $\left(\mathrm{Pa}, \mathrm{O}_{2} 9.4 \mathrm{kPa}\right)$ without $\mathrm{CO}_{2}$ retention at rest and a moderately reduced $D \mathrm{~L}, \mathrm{CO}(\sim 55 \%$ pred). Resting pulmonary function characteristics after randomisation did not show significant differences between the study groups (table 1). Furthermore, no changes were observed in these characteristics after training in any of the groups.

The baseline response to the incremental exercise test is also presented in table 1. As expected, exercise tolerance was substantially impaired. Peak $V^{\prime} \mathrm{O}_{2}$ averaged $54.8 \pm 3.4 \%$ pred in the IT group and $55.7 \pm$ $3.5 \%$ pred in the CT group. Peak $V^{\prime} \mathrm{E}$ amounted to $80 \pm 7$ and $82 \pm 7 \%$ of the predicted MVV for the IT and CT groups, respectively.

\section{Training programme}

Both groups of patients adhered to their exercise regimens reasonably well. The attendance rate at the exercise sessions averaged $90 \pm 4 \%$ for the IT group and $88 \pm 4 \%$ for the CT group. Examination of the groups' mean training intensities for each week of the programme revealed that approximately the same total amount of work was performed in the two types of training (fig. 1). The mean programme intensity of the 

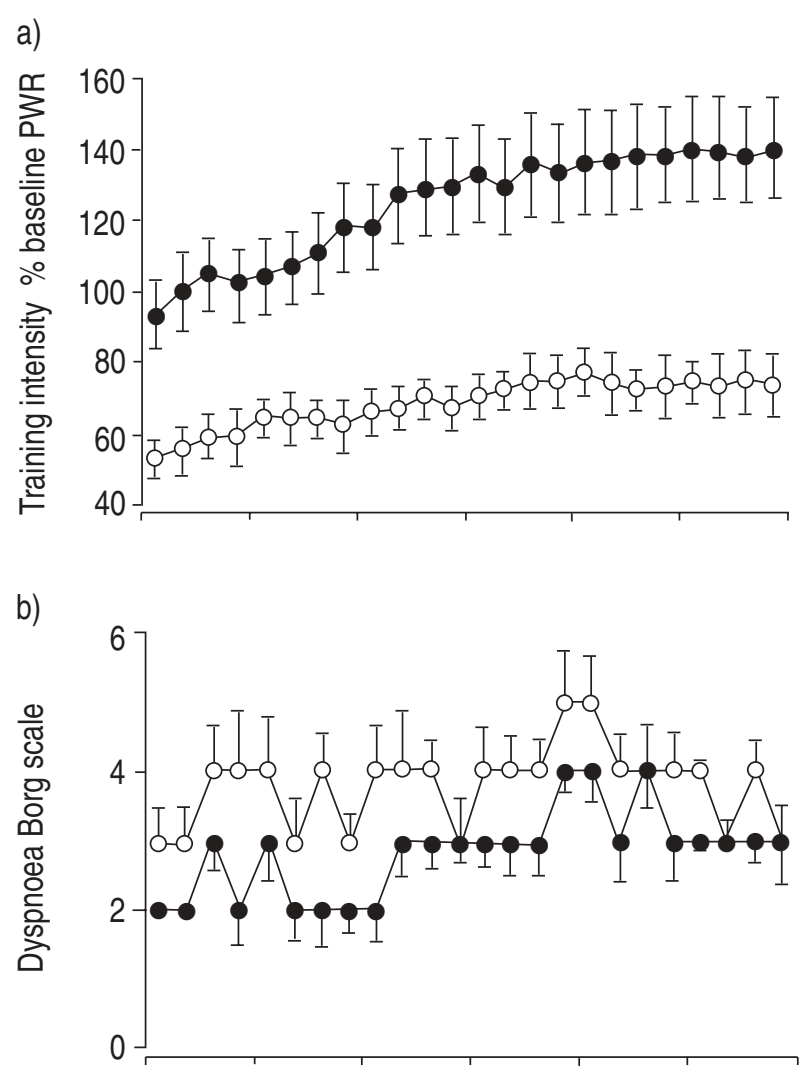

c)

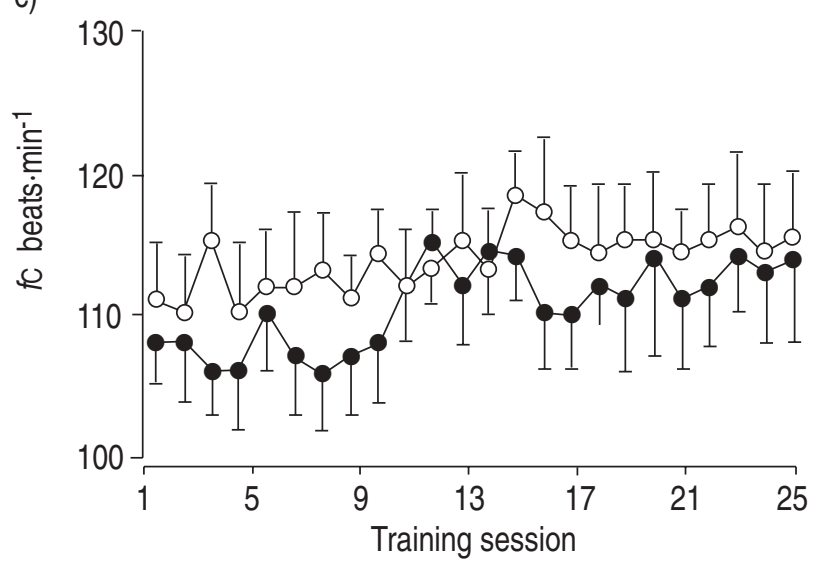

Fig. 1.-a) Group training intensities sustained during the training sessions each week of the programme, b) dyspnoea scores (Borg scale) and c) cardiac frequency $(f c)$; over the last $5 \mathrm{~min}$ of each 40-min training session ( $\bullet$ interval training group; $\bigcirc$ : continuous training group). Data are presented as mean \pm SEM. PWR: peak work-rate.

IT group (124 $\pm 3 \%$ PWR) was approximately double that of the CT group ( $67 \pm 1 \%$ PWR). Furthermore, $f \mathrm{C}$ response was similar between the two groups, whereas perception of dyspnoea was significantly lower during interval training $(\mathrm{p}<0.01)$.

\section{Incremental exercise test}

At the outset of the study, both groups were well matched with respect to mean peak exercise responses (table 1). After the end of the training programme, PWR was significantly increased by 14 and $13 \mathrm{~W}$ (25 and 23\%) in the IT and CT groups, respectively, whereas the slope of $V^{\prime} \mathrm{O}_{2} / \mathrm{WR}$ was significantly reduced by 12 and $9 \%$ in the IT and CT groups, respectively (fig. 2). Furthermore, the $V^{\prime} \mathrm{O}_{2}$ at which the LT occurred (detected before and after training in 14 out of 18 patients in both training groups) significantly increased in the IT and CT groups by 0.11 and $0.12 \mathrm{~L} \cdot \mathrm{min}^{-1}(14$ and $15 \%)$, respectively. These changes were accompanied by trends of improvement in the peak values of $V^{\prime} \mathrm{O}_{2}, V^{\prime} \mathrm{E}, f \mathrm{R}$, and $f \mathrm{C}$ (fig. 2). For each patient, peak physiological measurements at the WR attained at the end of tolerable exercise in the baseline ergometer test were compared to measurements at an identical WR during the outcome test. Significant mean reductions in $V^{\prime} \mathrm{E}$ (IT, $\left.4.1 \mathrm{~L} \cdot \mathrm{min}^{-1}(11 \%) ; \mathrm{CT}, 3.9 \mathrm{~L} \cdot \mathrm{min}^{-1}(11 \%)\right), V^{\prime} \mathrm{O}_{2}$ (IT, $0.12 \mathrm{~L} \cdot \mathrm{min}^{-1}(11 \%)$; CT, $0.13 \mathrm{~L} \cdot \mathrm{min}^{-1}(12 \%)$ ), $V^{\prime} \mathrm{CO}_{2} \quad\left(\mathrm{IT}, 0.10 \mathrm{~L} \cdot \mathrm{min}^{-1}(11 \%) ; \mathrm{CT}, 0.12 \mathrm{~L} \cdot \mathrm{min}^{-1}\right.$ $(13 \%)), f R$ (IT, 5 breaths $\cdot \mathrm{min}^{-1}(16 \%)$; CT, 5 breath$\mathrm{s} \cdot \mathrm{min}^{-1}(15 \%)$ ), dyspnoea score (IT, $1.9(42 \%)$; CT, $1.7(41 \%))$ and $f \mathrm{C}$ (IT, 13 beats $\cdot \mathrm{min}^{-1}(10 \%)$; CT, 10 beats $\mathrm{min}^{-1}(8 \%)$ ) were found (fig. 2). The magnitude of improvement in these parameters was not significantly different between the two groups. Furthermore, in the light of the shift in the $V^{\prime} \mathrm{O}_{2} / \mathrm{WR}$ relationship, pre- and post-training measurements at the same metabolic $\left(V^{\prime} \mathrm{O}_{2}\right)$ level were compared in both groups. After training, at pretraining $V^{\prime} \mathrm{O}_{2}$, there were no significant changes in the recorded variables, with the exception of WR, which was significantly higher, by 9 and $12 \mathrm{~W}$ (16 and 20\%), in the IT and CT groups, respectively (fig. 3).

\section{Quality of life}

Differences between pre- and post-training CRDQ questionnaire scores are presented in figure 4 . There were no significant differences between the two groups at the outset of the study. Following completion of the programme, there was a significant improvement in the CRDQ overall score in both groups (IT, $11(14 \%)$; CT, $15(19 \%))$. Patients in both groups showed clinically significantly improved scores for the domains of dyspnoea and fatigue (i.e. 2.5 and 2 points, respectively) [17]. The magnitude of improvement was not significantly different between the two groups (fig. 4).

\section{Discussion}

The present study demonstrates that a training programme consisting of maximal-intensity interval exercise sessions as part of pulmonary rehabilitation yields substantial improvements in measures of exercise tolerance and QoL. The improvements were accompanied by physiological and exertional changes at a given level of exercise, including reductions in both ventilatory requirement and sense of breathlessness. Furthermore, the comparison of the effects of maximal-intensity IT versus moderately intense CT on 

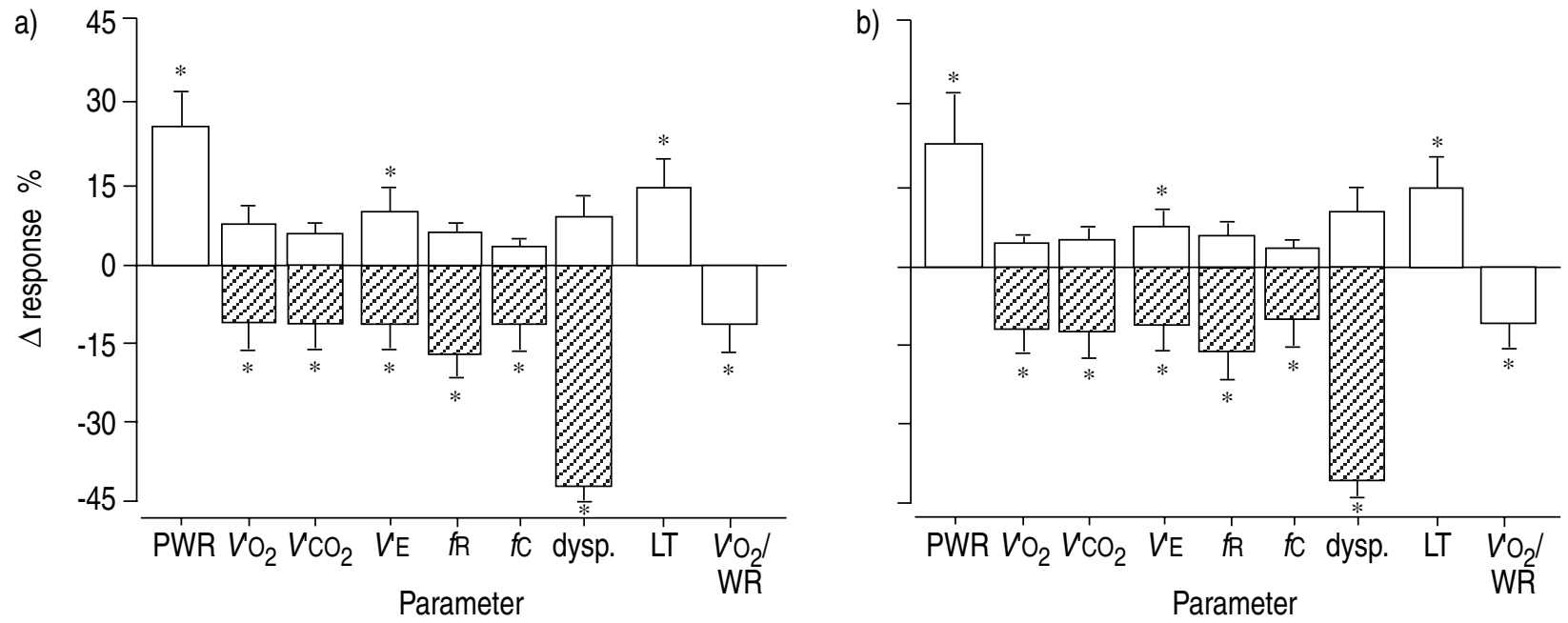

Fig. 2.-Difference $(\Delta)$ in physiological responses at baseline peak work-rate (PWR; $\square$ ) and at an identical work-rate (WR; $\mathbb{Z}$ ) from initial PWR exercise during the incremental cycle ergometer test produced by a) interval training and b) continuous training. $V^{\prime} \mathrm{O}_{2}$ : oxygen uptake; $V^{\prime} \mathrm{CO}_{2}$ : carbon dioxide output; $V^{\prime} \mathrm{E}$ : minute ventilation; $f \mathrm{R}$ : respiratory frequency; $f \mathrm{C}$ : cardiac frequency; dysp.: end-exercise dyspnoea score; LT: lactate threshold; $V^{\prime} \mathrm{O}_{2} / \mathrm{WR}$ : slope of $V^{\prime} \mathrm{O}_{2} / \mathrm{WR}$. *: ${ }^{*}<0.05$ within group.

exercise tolerance, sense of breathlessness and QoL revealed that both modalities induced improvements of a very similar magnitude.

The necessity to investigate the efficacy of IT derives from the fact that ventilatory response dynamics constrain tolerance to high-intensity exercise in patients with moderately severe and severe COPD [1]. Studies in healthy people have shown that repeated maximal-intensity exercise bouts, allowing corresponding short rest intervals between bouts, can be tolerated for an extensive period [7] and yield similar physiological benefits to extended high-intensity continuous exercise $[22,23]$. Furthermore, as shown in healthy individuals [24], the metabolic response to interval exercise is very similar to that to continuous exercise at half the WR, suggesting that the relief intervals between bouts of hard work in IT bear

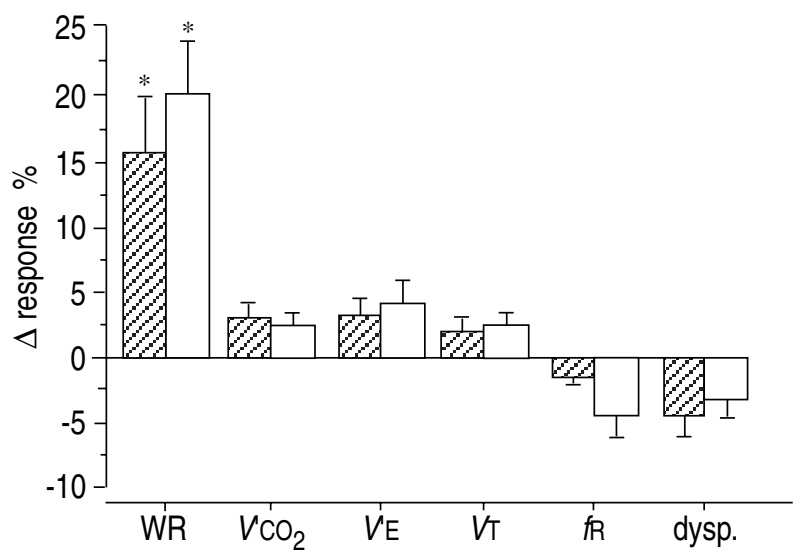

Fig. 3.-Difference $(\Delta)$ in recorded responses before and after training at pretraining oxygen uptake $\left(V^{\prime} \mathrm{O}_{2}\right)$ level during the incremental cycle ergometer test produced by interval training $(\mathbb{Z})$ and continuous training $(\square)$. WR: work-rate; $V^{\prime} \mathrm{CO}_{2}$ : carbon dioxide output; $V^{\prime} \mathrm{E}$ : minute ventilation; $V_{\mathrm{T}}$ : tidal volume; $f \mathrm{R}$ : respiratory frequency; dysp.: end-exercise dyspnoea score. ${ }^{*}: \mathrm{p}<0.05$ within group. special importance with regard to the successful application of maximal-intensity training.

The magnitude of improvement in PWR in the IT group $(25 \%)$ is comparable to that described by Gosselink et al. [10] and Coppoolse et al. [11]. In addition, consistent with their and previous results from 12 reported randomised controlled trials [3] is the lack of significant improvement in recorded peak cardiovascular and respiratory responses. However, the present results differ importantly from those of CoppoOlse et al. [11] in that patients assigned to the interval group demonstrated a reduction in ventilatory requirement and dyspnoea scores in response to identical levels of exercise in the incremental exercise tests (fig. 2). It is likely that the reduction in ventilatory requirement is multifactorial and relates to improved oxidative capacity $[4,25]$, altered breathing pattern [6] and/or improved work efficiency [26]. The significant training-induced increase in LT is probably

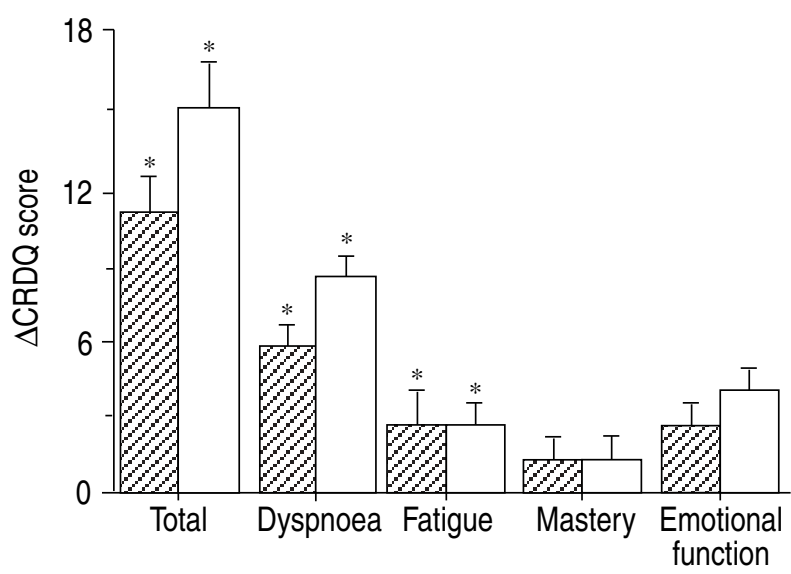

Fig. 4. - Change from baseline $(\Delta)$ of Chronic Respiratory Disease Questionnaire (CRDQ) total score and domain (dyspnoea, fatigue, mastery and emotional function) scores produced by interval training $(\mathbb{Z})$ and continuous training $(\square)$. * $\mathrm{p}<0.05$ within group. 
indicative of improved efficiency of peripheral muscle oxygen extraction $[4,27]$. In addition, the possibility of a more efficient breathing pattern and decreased hyperinflation following IT cannot be excluded; mean $f \mathrm{R}$ was significantly lower and $V \mathrm{~T}$ marginally higher at an identical WR during the incremental ramp test (fig. 2). The reduction in $f \mathrm{R}$ by 16 and $15 \%$ in the IT and CT groups, respectively, would be expected to reduce thoracic gas entrapment and the rate of expiratory muscle recruitment and result in decreased work of breathing and exertional breathlessness [26]. It is also likely that the reduction in ventilatory requirement following IT is associated with a reduced metabolic requirement and recruitment of active muscle mass [20] and hence an improvement in mechanical efficiency, shown by the reduction in the slope of $V^{\prime} \mathrm{O}_{2} / \mathrm{WR}$ (fig. 2) [26, 28] and confirmed by the absence of significant changes in physiological variables at a given metabolic $\left(V^{\prime} \mathrm{O}_{2}\right)$ level (fig. 3). Nevertheless, after training, patients in both groups were able, at a given metabolic $\left(V^{\prime} \mathrm{O}_{2}\right)$ rate, to perform external work at a higher rate (fig. 3).

The discrepancy between the present study and that of COPPOOLSE et al. [11] regarding the efficacy of IT in inducing physiological changes is possibly due to the prescription of interval exercise. In their study, patients who were assigned to the interval group received only nine blocks of 1 -min high-intensity $(90 \%$ PWR) exercise which were alternated with nine blocks of 2-min low-intensity (45\% PWR) exercise. Furthermore, total work output during the training period was kept constant without being regularly adjusted to parallel the improvement in physical fitness and thus to maintain relative training intensity constant $[19,20]$. In the present study, the training intensity progressively increased in each patient. Notwithstanding, $f \mathrm{C}$ did not increase significantly during the training period (fig. 1), suggesting that, as fitness level improved and WR increased, the relative exercise intensity remained unchanged.

Consistent with the results of the studies of Gosselink et al. [10] and Coppoolse et al. [11] in patients with COPD and others on healthy populations [21, 22] is the lack of significant differences between the two training groups. Both training modalities resulted in similar percentages of improvement in PWR, which fall within the range of improvement normally reported $(15-30 \%)$ for CT [3] and IT programmes $[10,11,21,22]$. A significant increase in LT occurred as a result of training in both groups, suggesting that muscle oxidative capacity was enhanced regardless of the type of training that was applied. The results at identical WRs during the incremental WR tests corroborate the PWR tests in that CT and IT produce nearly identical responses. As can be seen in figure $2, V^{\prime} \mathrm{E}, f \mathrm{R}, f \mathrm{C}$ and dyspnoea scores decreased by a significant amount and to a comparable degree. The magnitude of reduction in the above variables confirms the results of the studies of Maltais et al. [5] and CAsABURi et al. [6] who applied either moderate $(50-60 \%)$ [5] or high-intensity $(80 \%)$ [6] continuous exercise training.

It might be wondered how the $100 \%$ IT would compare to training at $80 \%$ of maximum rather than
$50 \%$ of maximum. Early studies in healthy subjects have shown that the physiological responses to CT at either $70 \%$ [22] or $80 \%$ [21] of peak exercise capacity were not significantly different to those of IT at $100 \%$ of peak work capacity, when the total workload was equated per training session. Furthermore, in patients with moderate airflow obstruction (FEV1 46\% pred), NEDER et al. [1] showed that the highest level of continuous exercise that could be sustained for a relatively long period of time (20 min) was equivalent to $82 \%$ of PWR. Therefore, providing that patients assigned to the CT group in the present study were able to sustain high-intensity ( $80 \%$ of baseline PWR) exercise for $40 \mathrm{~min}$ from the beginning of the programme, it would be expected that no significant differences in the magnitude of improvements between the IT and CT modalities would be found.

The improvements in measures of exercise tolerance were extrapolated to improved QoL, since the CRDQ questionnaire overall score increased in both groups after rehabilitation (fig 4). Most notably, patients demonstrated objective improvements in domestic function, being able to perform daily activities with less dyspnoea, as evidenced by the significant change in score for this domain. The finding that the improvement in overall CRDQ score was comparable in both groups is important, especially when it is considered that both groups experienced very similar physiological training effects accompanied by a similar degree of reduction in breathlessness.

The most interesting feature of the present investigation was the almost exact replication of results following two different training methods in patients with moderately severe COPD. The investigators attribute this to the following variables controlled during the trial: 1) the initial level of exercise capacity and disease severity were equated; 2) the exercise training load of each group was gradually increased but remained fairly comparable for both groups; and 3) the training load (i.e. intensity and duration of training sessions), as well as the total duration of the programme, was within the range advocated by a number of researchers in order to secure adequacy [3-6, 28]. However, based on the results of a previous study [29] and in view of the cost, resource effort and patient compliance issues involved when conducting a rehabilitation programme, it was decided to limit training frequency to twice weekly in an attempt to ensure high rates of attendance. It is highly likely that a higher weekly training frequency would have been more effective in terms of inducing measurable improvements in physiological responses not only in response to identical levels of exercise as shown above but also at a given metabolic $\left(V^{\prime} \mathrm{O}_{2}\right)$ level.

\section{Potential implications for training prescription in chronic obstructive pulmonary disease patients}

Interval exercise allows work of maximal intensity to be performed with a relatively low perception of dyspnoea (fig. 1) by the introduction of properly spaced short exercise and rest periods. This concept has at least two important implications with regard 
to how pulmonary rehabilitation might be given to the COPD patient. First, it may explain why patients with severe airflow obstruction, in spite of a reduced capacity for work, can remain in jobs involving heavy manual labour or successfully participate in exercise rehabilitation programmes. As long as they are free to choose the optimal length of exercise and rest periods, the acute load on respiration may not exceed the limits of their reduced capacity. Secondly, it is possible to select the proper load and exercise and rest periods in such a manner that the main demand is centred on both muscle strength and oxygen-transporting organs without significantly mobilising anaerobic processes (typically exercise bouts of $\leqslant 30 \mathrm{~s}$ ) [30].

In conclusion, the present investigation provides not only an additional perspective of the conventional physiologically based principles of exercise prescription for patients with chronic obstructive pulmonary disease but also endorses the benefit of commonly used training strategies. As understanding of what constitutes a training load adequate to induce physiological training effects is still evolving, further research is required to evaluate the efficacy and the applicability of different interval-based exercise protocols. in patients with chronic obstructive lung disease. $A m$ Rev Respir Dis 1991; 143: 9-18.

5. Maltais F, LeBlanc $\mathrm{P}$, Jobin J, et al. Intensity of training and physiologic adaptation in patients with chronic obstructive pulmonary disease. Am J Respir Crit Care Med 1997; 155: 555-561.

6. Casaburi R, Porszasz J, Burns MR, Carithers ER, Chang RSY, Cooper CB. Physiologic benefits of exercise training in rehabilitation of patients with severe chronic obstructive pulmonary disease. $\mathrm{Am}$ J Respir Crit Care Med 1997; 155: 1541-1551.

7. Astrand I, Astrand PO, Christensen EH, Hedman R. Intermittent muscular work. Acta Physiol Scand 1960; 48: 448-453.

8. Christensen EH, Hedman R, Saltin B. Intermittent and continuous running. Acta Physiol Scand 1960; 50: 269-287.

9. Fox EL, Robinson S, Wiegman DL. Metabolic energy sources during continuous and interval running. $J$ Appl Pysiol 1969; 27: 174-178.

10. Gosselink R, Troosters T, Decramer M. Exercise training in COPD patients: interval training vs. endurance training (abstract). Eur Respir J 1998; 12: Suppl. 28, 2s.

11. Coppoolse R, Schols AMWJ, Baarends EM, et al. Interval versus continuous training in patients with severe COPD: a randomized clinical trial. Eur Respir $J$ 1999; 14: 258-263.

12. Gardner RM, Hankinson JL, Clausen JL, Crapo RO, Johnson RO Jr, Epler GR. American Thoracic Society standardization of spirometry - 1987 update. Am Rev Respir Dis 1987; 136: 1285-1298.

13. Juthong S, Lam WK, Chuaychoo B, Hanen JE, Stringer WW, Wasserman K. The effect of airflow obstruction on exercise capacity and breathing reserve in COPD. Am J Respir Crit Care Med 2001; 163: A266.

14. Borg GAV. Psychophysical bases of perceived exertion. Med Sci Sports Exerc 1982; 14: 377-381.

15. Jones NJ. Appendix D. Normal standards. In: Clinical Exercise Testing. 3rd Edn. Philadelphia, W.B. Saunders Company, 1988; pp. 243-247.

16. Beaver WL, Wasserman K, Whipp BJ. A new method for detecting anaerobic threshold by gas exchange. J Appl Physiol 1986; 60: 2020-2027.

17. Guyatt GH, Berman LB, Townsend M, Pugsley SO, Chambers LW. A measure of quality of life for clinical trials in chronic lung disease. Thorax 1987; 42: 773-778.

18. McArdle WD, Katch FI, Katch VL. Training anaerobic and aerobic power. In: Exercise Physiology. 3rd Edn. Malvern, PA, Lea and Febiger, 1991; pp. 393-416.

19. Davies CTM, Knibbs AV. The training stimulus: the effects of intensity duration and frequency of efforts on maximum aerobic power output. Int $Z$ Angew Physiol 1971; 29: 299-305.

20. Saltin B, Nazar K, Costill DL, et al. The nature of the training response; peripheral and central adaptations to one-legged exercise. Acta Physiol Scand 1976; 96: 289-305.

21. Cunningham DA, McCrimmon D, Vlach LF. Cardiovascular response to interval and continuous exercise in women. Eur J Appl Physiol 1979; 41: 187-197.

22. Eddy DO, Sparks KL, Adelizi DA. The effects of continuous and interval training in women and men. Eur J Appl Physiol 1977; 37: 83-92.

23. McKenzie DC, Fox EL Cohen K. Specificity of 
metabolic and circulatory responses to arm or leg interval training. Eur J Appl Physiol 1977; 39: 241-248

24. Saltin B, Essen B. Muscle glycogen, lactate, ATP, and $\mathrm{CP}$ in intermittent exercise. In: Pernow $\mathrm{B}$, Saltin $\mathrm{B}$, eds. Muscle Metabolism During Exercise. New York, NY, Plenum Press, 1971; pp. 419-424.

25. Maltais F, LeBlanc P, Simard C, et al. Skeletal muscle adaptation to endurance training in patients with chronic pulmonary disease. Am J Respir Crit Care Med 1996; 154: 442-447.

26. O'Donnell DE, McGuire M, Samis L, Webb KA. The impact of exercise reconditioning on breathlessness in severe chronic airflow limitation. Am J Respir Crit Care Med 1995; 152: 2005-2013.

27. Sala E, Roca J, Marrades M, et al. Effects of endurance training on skeletal muscle bioenergetics in chronic obstructive pulmonary disease. Am J Respir Crit Care Med 1999; 159: 1726-1734.

28. O'Donnell DE, McGuire M, Samis L, Webb KA. General exercise training improves ventilatory and peripheral muscle strength and endurance in chronic airflow limitation. Am J Respir Crit Care Med 1998; 157: 1489-1497.

29. Vogiatzis I, Williamson AF, Miles J, Taylor IK. Physiological responses to moderate exercise workloads in a pulmonary rehabilitation program in patients with chronic airflow obstruction. Chest 1999; 116: 1200-1207.

30. Astrand PO, Rodahl K. Physical Training. In: Astrand PO, Rodahl K, eds. Textbook of Work Physiology. New York, NY, McGraw-Hill, 1986; pp. 412-476. 